\title{
COMPARATIVE ANALYSIS OF THE FORMATION OF MILITARY PROFESSIONAL SKILLS IN THE CADETS TO BE TRAINED IN LOGISTICS SPECIALIZATIONS
}

\author{
Venelin Terziev ${ }^{1 \star}$, Nikolay Nichev ${ }^{2}$, Plamen Bogdanov ${ }^{3}$ \\ ${ }^{1}$ Corresponding Member of the Russian Academy of Natural History, Moscow, Russia, Professor, \\ Ph.D., D.Sc. (National Security), D.Sc. (Ec.), University of Rousse, Rousse, Bulgaria; National \\ Military University, Veliko Tarnovo, Bulgaria; University of Telecommunications and Post, Sofia, \\ Bulgaria, terziev@skmat.com \\ ${ }^{2}$ Colonel Associate Professor, Ph.D., National Military University, Veliko Tarnovo, Bulgaria, \\ nicheff@gmail.com \\ ${ }^{3}$ Brigadier General, Ph.D., National Military University, Veliko Tarnovo, Bulgaria, \\ ${ }^{*}$ Corresponding author
}

\begin{abstract}
The social, political and economic changes in the Bulgarian society leave their traces in all spheres of the public life, in particular of the military education system. The implemented in the Republic of Bulgaria reforms assign to the Vasil Levski National Military University the task to train logistic officers at a high level of professional skills, who are ready to solve efficiently the assigned tasks.

The specific character of the logistic officers' activity sets increased requirements to their management skills and abilities and to the management effectiveness, related to them. In connection with this the disclosure of holdings of cadets from different specializations logistics management, organizational and communication skills is the topical trend to disclose ways to improve military professional training and formation of readiness for a timely and quality management decision making.

The research target is the military professional training of the future logistic officers, while the developed in the course of their military professional training management skills, management, organizational and communication skills of the future logistic officers are subject of research. The research aim is to analyze the acquired in the course of the military professional training of the future logistic officers management skills and abilities and the related to them management effectiveness. The methods of research are: a theoretical analysis of the military education literature is used during the research; also the methods of inquiry, statistics, substantiation and general conclusion.
\end{abstract}

Keywords: military training, training of cadets. 


\section{INTRODUCTION}

The social, political and economic changes in the Bulgarian society leave their traces in all spheres of the public life, in particular of the military education system. The implemented in the Republic of Bulgaria reforms assign to the Vasil Levski National Military University the task to train logistic officers at a high level of professional skills, who are ready to solve efficiently the assigned tasks.

The specific character of the logistic officers' activity sets increased requirements to their management skills and abilities and to the management effectiveness, related to them. In connection with this the disclosure of holdings of cadets from different specializations logistics management, organizational and communication skills is the topical trend to disclose ways to improve military professional training and formation of readiness for a timely and quality management decision making.

\section{GENERAL LAYOUT OF THE RESEARCH}

The research work was carried out in the Land forces Faculty of the Vasil Levski National Military University during the period $2014-2016$.

The research comprises Cadets from the logistical specialties with specializations „Logistic troops and fuel and lubrication materials"(FLM), „Movement and transport" and "Material resources, movement and transport".

The examined group consists of 42 people out of 42 , separated into the following subgroups (SG): SG1 - 16 Cadets, SG2 - 6 Cadets, SG3 - 20. The summarized data of the examined group are shown below in Table 1.

Table 1. Summarized data of the examined group.

\begin{tabular}{|c|c|c|}
\hline $\begin{array}{c}\text { Sub- } \\
\text { group }\end{array}$ & Logistical specializations & $\begin{array}{c}\text { Number of } \\
\text { trainees }\end{array}$ \\
\hline SG 1 & Logistic troops and FLM & 16 \\
\hline SG 2 & Movement and transport & 6 \\
\hline SG 3 & Material resources, movement and transport & 20 \\
\hline
\end{tabular}

The research was carried out at three stages:

- first stage - examination of the literature and selection of the research methodology.

- second stage - conduct of the study. The empirical information was collected using the inquiry method in the format of a direct group questionnaire.

- third stage - analysis of the obtained results and drawing of conclusions.

\section{RESEARCH OF THE MANAGEMENT SKILLS}

It can be concluded from the analysis of the accessible literature, that the management activity of the Logistic Officer in the units, compared to the Commanders of fighting units, is more versatile and has the specific, which must be taken into consideration in the training process of the future Logistic Officers (Nichev, 2015, pp. 253-257) (Petrova, 2016, pp. 113-119). The management activity takes a specific place in the structure of the military professional activity of the logistic officers. This place is predetermined by the versatile characteristic of the contents, of the kind and peculiarity of the solved tasks during the performance of their official obligations and represents a necessary condition for a successful official activity (Terziev V. K., 2017a).

A methodology of identifying of the personally possessed management competences and abilities and the grade of their display was used in the research of the management skills. The methodology comprises 50 questions, each of them having two possible answers to choose from (Terziev V. K., Research of the communication and organization management competences of the cadets during their military professional training., 2017b). Having analyzed the given answers of the examined persons, a conclusion is drawn if they possess the required personal skills of a good manager. In accordance with the given key, the total sum of the obtained points is determined. For the evaluation the following points result is being used:

- up to 25 points - incomplete and less pronounced management skills. 
- from 26 up to 35 points - well expressed management skills.

- from 36 up to 40 points - highly expressed management skills.

- more than 40 - authoritarian management style.

The results of the conducted research are listed in Table 2.

Insert your heading text and choose the appropriate heading level from the style menu. Insert your heading text and choose the appropriate heading level from the style menu. Insert your heading text and choose the appropriate heading level from the style menu. Insert your heading text and choose the appropriate heading level from the style menu. Insert your heading text and choose the appropriate heading level from the style menu. Insert your heading text and choose the appropriate heading level from the style menu. Insert your heading text and choose the appropriate heading level from the style menu. Insert your heading text and choose the appropriate heading level from the style menu. Insert your heading text and choose the appropriate heading level from the style menu. Insert your heading text and choose the appropriate heading level from the style menu. Insert your heading text and choose the appropriate heading level from the style menu. Insert your heading text and choose the appropriate heading level from the style menu. Insert your heading text and choose the appropriate heading level from the style menu.

Table 2. Levels of management skills in the examined subgroups

\begin{tabular}{|l|c|c|c|}
\hline Levels of management skills & SG 1 & SG 2 & SG 3 \\
\hline incomplete and less expressed & 4 & 2 & 6 \\
\hline well expressed & 9 & 3 & 10 \\
\hline highly expressed & 1 & & 3 \\
\hline authoritarian style & 2 & 1 & 1 \\
\hline
\end{tabular}

The results of the conducted research show, that a big part of the examined persons demonstrate incomplete or less expressed management competences and skills - specialization "Logistics troops and SML" demonstrated the lowest respectively by $25 \%$ and the highest is specialization "movement and transport" - 33.3\%. The fact, which disturbs, is that no Cadets possess highly expressed management skills in specialization "Movement and transport”. In specializations "Logistic troops and fuel and lubrication materials (FLM) and "Material resources, movement and transport" the levels are too low - respectively 6.3\% and $15.0 \%$. The percentage of the levels of management skills of the whole group is illustrated in Fig. 1.

Figure 1. Percentage ration of the levels of management skills of the whole examined group.

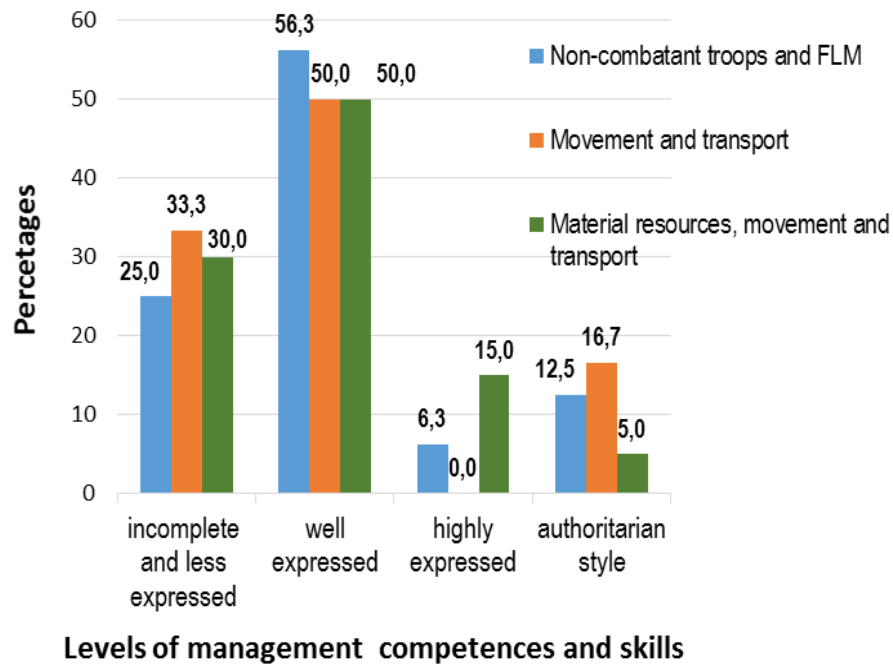

The main task of the education and training process in the Vassil Levski National Military University is to increase the share of Cadets with well or highly expressed management competences and skills. The formation of well and highly expressed management skills in the trainees in logistics specializations in the Vassil Levski National Military University is illustrated in Fig.2. 
Figure 2. Results from the examined well and highly expressed management skills in logistics specializations.

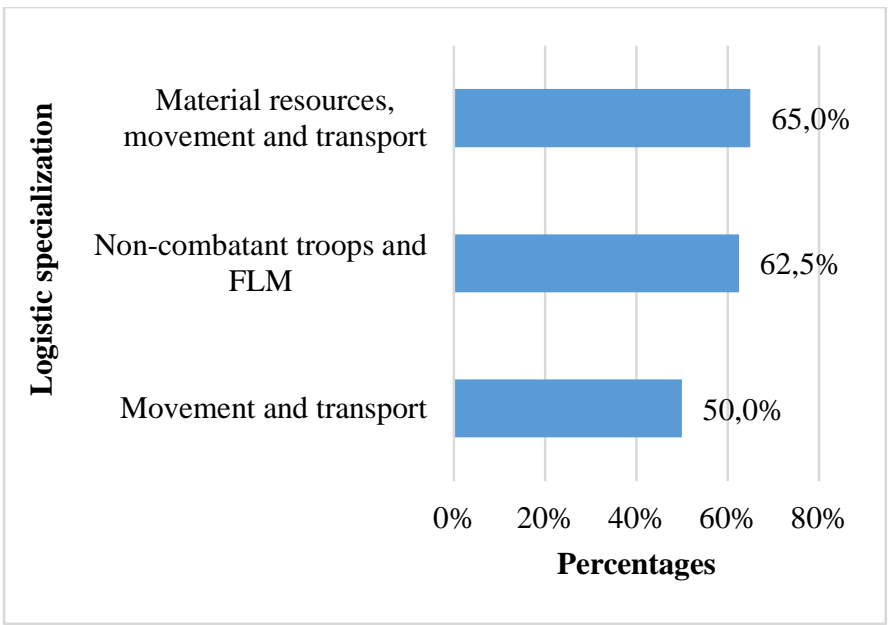

Insert your heading text and choose the appropriate heading level from the style menu. Insert your heading text and choose the appropriate heading level from the style menu. Insert your heading text and choose the appropriate heading level from the style menu. Insert your heading text and choose the appropriate heading level from the style menu. Insert your heading text and choose the appropriate heading level from the style menu. Insert your heading text and choose the appropriate heading level from the style menu.

The results show that in the studied group specialization "Material resources, movement and transport" in the utmost allows the formation of well and highly expressed managerial skills in logistics specialists.

As a general regularity of all examined sub-groups appears the high share of the incomplete and less expressed management competences and skills. Terziev and Nichev consider that most probably this fact is due to the preferred subjects for general military and technical training of the military speciality and due to training subjects with emphasized logistic themes and learning of a smaller number of management disciplines during the civilian specialization (Terziev V. K., Research of the communication and organization management competences of the cadets during their military professional training., 2017b).

\section{RESEARCH OF THE COMMUNICATION SKILLS}

The methodology of V. Sinyavsky, V. Fedoroshin was used during the research of the communication and organization management competences. With the help of calculations of the evaluation ratios separately for the communication and for the organization competences the levels of the relevant abilities are being determined. The calculated ratios may vary between 0 and 1 . Indices close to 1 show a high level of communication and organization skills, those which are close to 0 - low level. The main indices for communication and organization abilities are represented in the form of score, giving evidence of the different levels of the examined skills (Terziev V. K., Research of the management skills and abilities and of the management effectiveness of the cadets, 2017c).

In Table 3 are given the results of the carried out research about the communication skills of the future logistic officers.

Table 3. Level of communication skills according to the examined subgroups

\begin{tabular}{|l|c|c|c|}
\hline \multicolumn{1}{|c|}{ Subgroup } & SG & SG & SG 3 \\
communication skills & 1 & 2 & (ow \\
\hline low & & & 1 \\
\hline below the average & 1 & & 2 \\
\hline average & 3 & 1 & 6 \\
\hline high & 2 & & 4 \\
\hline very high & 10 & 5 & 7 \\
\hline
\end{tabular}

The percentage of the levels of communication skills of the whole examined group is shown on Fig. 3 . 
Figure3 Percentage of the levels of communication skills of the whole surveyed group.

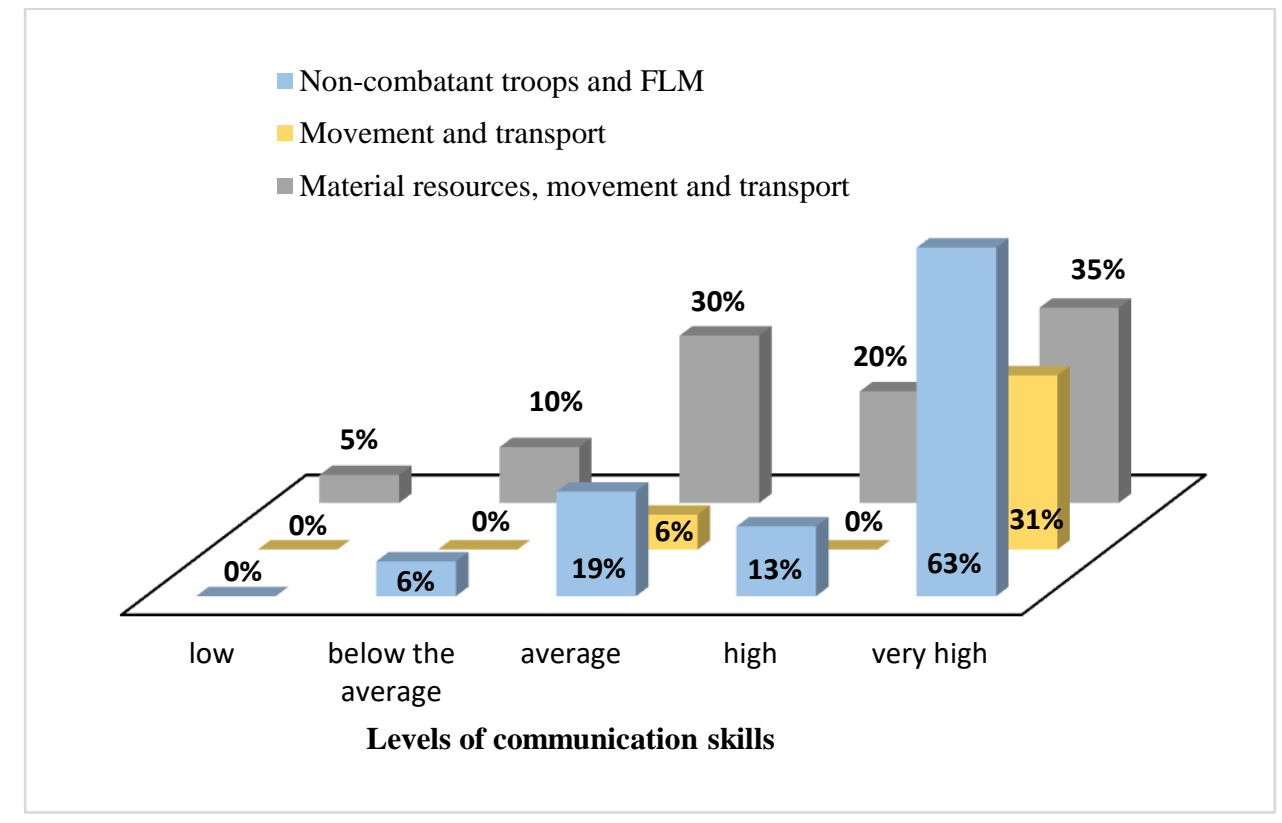

$2,4 \%$ of the examined are characterized with a level of display of communication skills, which is below the average. The cadets, who are characterized with a low level of display of communication skills, are $7,1 \%$ of all the examined persons. The examined persons, who belong to the scale with an average level of display of communication skills, are $23,8 \%$ of the examined trainees. $14,3 \%$ of the future non-combatant officers are characterized with a high level of display of communication skills. Persons, who have received the highest score, possess a very high level of communication skills - $55 \%$ of the examined persons belong here.

The educational process at the Vasil Levski National Military University is directed at the increase of the share of the high and of the very high level of display of communication skills. Such skills were demonstrated by $66,7 \%$ of all trainees from the logistical specializations.

The developing of high and very high communication skills in the trainees from different logistical specializations is shown on Fig.4.

Figure 4. Results of the examined high and very high communication skills according to the logistical specialization.

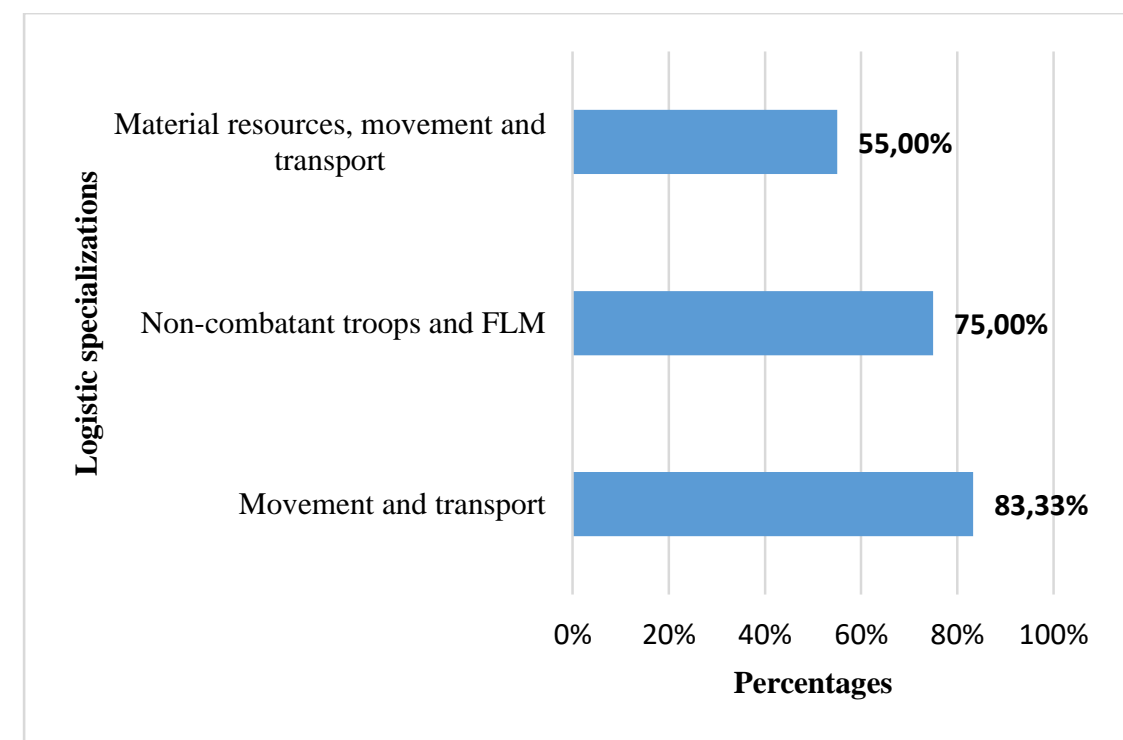

\section{RESEARCH OF THE ORGANIZATION SKILLS}

The results of the carried out research of the organization skills of the future logistic officers are shown in Table4. 
Table 4. Level of organization competences in the examined subgroups

\begin{tabular}{|l|c|c|c|}
\hline $\begin{array}{l}\text { Level of } \\
\text { organization } \\
\text { skills }\end{array}$ & $\begin{array}{c}\text { SG } \\
1\end{array}$ & $\begin{array}{c}\text { SG } \\
2\end{array}$ & $\begin{array}{c}\text { SG } \\
3\end{array}$ \\
\hline low & 3 & & 3 \\
\hline below the average & 1 & 1 & 5 \\
\hline average & 2 & & 2 \\
\hline high & 2 & 1 & 7 \\
\hline very high & 6 & 4 & 3 \\
\hline
\end{tabular}

The percentage of the levels of organization skills of the whole examined group is shown on Fig.5.

Figure 5. Percentage of the levels of organization skills of the whole examined group.

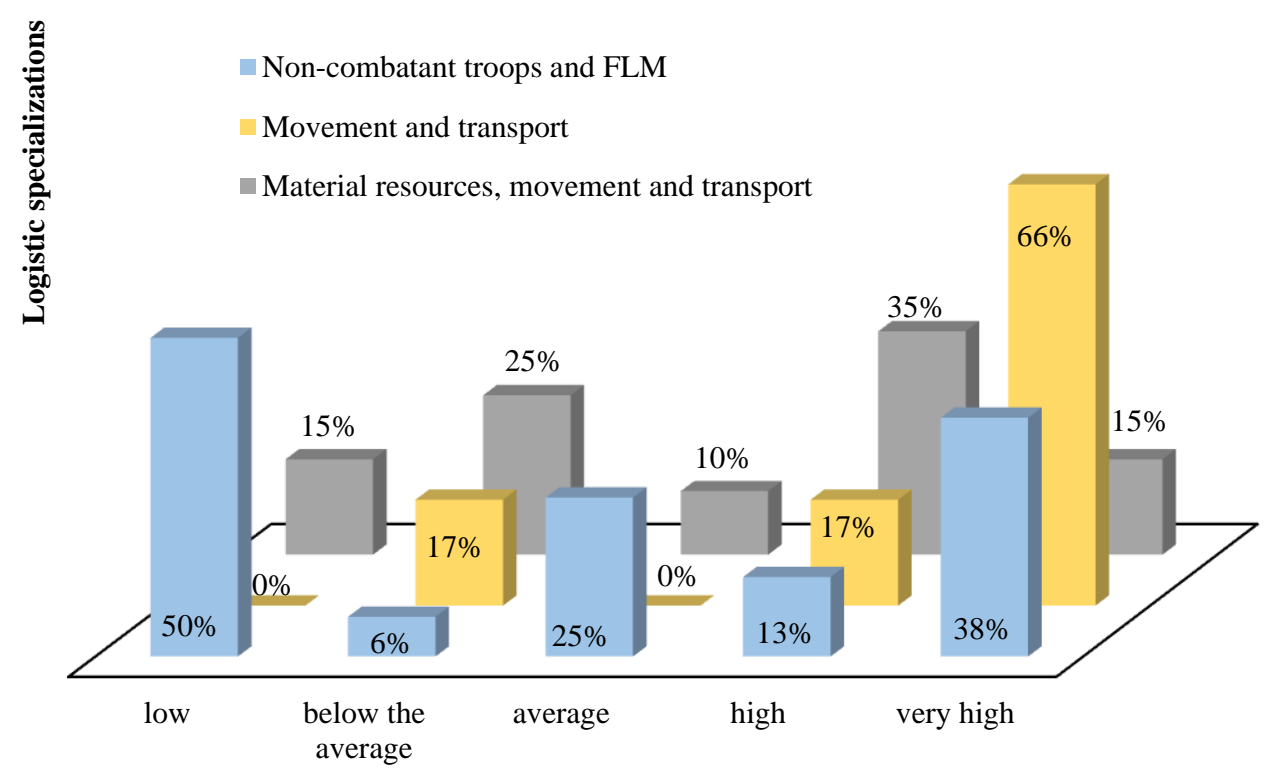

Levels of organization skills

$14,3 \%$ of the examined cadets possess a low level of display of the organization skills. The persons, who possess a level of display of the organization skills below the average, are $16,7 \%$. Persons, who are characterized with an average level of the organization skills, are $14,2 \%$. Persons with a high level of display of organization skills are $23.8 \%$ of the examined. The biggest share of the examined students $-31 \%$ possess a very high level of organization skills.

The developing of high and very high organization skills in the examined trainees from different logistical specializations at Vasil Levski National Military University is shown on Fig.6. 
Figure 6. Results of the examined high and very high organization skills according to the logistical specialization.

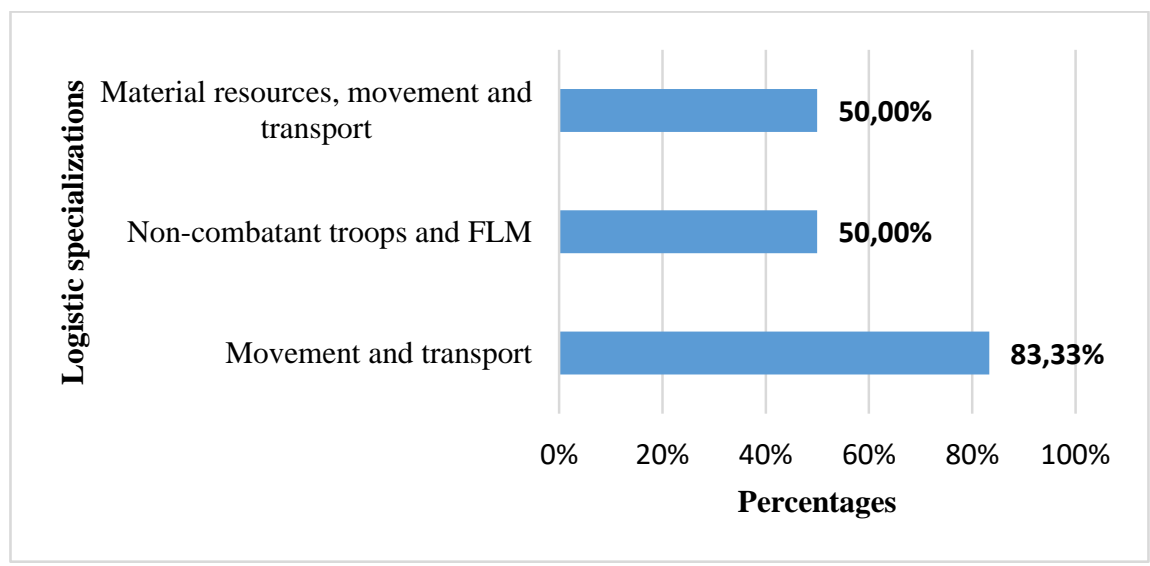

The analysis of the military professional skills shows, that the existing system for professional training of the future logistic officers allows the formation of appropriate management, organizational and communication skills in the trainees. It's necessary to direct the efforts of the academic staff to improve curricula with management topics and further development of the practical application of acquired skills of cadets of logistics specializations.

\section{CONCLUSION}

As e result of the carried out analysis the following conclusions can be drawn:

1. The results show that specialization "Material resources, traffic and transportation" to the greatest extent allowing the formation of appropriate managerial skills in the logistics specialists.

2. The curriculum of specialization "Movement and transport" provides the best conditions for the formation of appropriate communication and organization skills in logistics specialists.

3. Increasing the military professional management skills can be achieved by selecting and integrating appropriate courses of logistical specializations "Movement and transport" and "Material resources, movement and transport" in the development of new curricula for training future logistics officers.

\section{REFERENCES LIST}

Nichev, N. B. (2015). Professional training of future logistics officers at National Military University of Bulgaria. Sibiu, Romania: Knowledge Based Organization International Conference, "Nicolae Balcescu" Land forces academy.

Petrova, E. (2016). Specific Subjects of License Academic Program - an Important Stage of Professional Development of Future Military Leaders at the National Military University (Vol. 6). The Annals of Spiru Haret University.

Terziev, V. K. (2017a). Developing of readiness for organizational activity in the cadets. Prague, Czech Republic: CBU International Conference: Innovations in Science and Education.

Terziev, V. K. (2017b). Research of the communication and organization management competences of the cadets during their military professional training. Langkawi, Malaysia: 3rd International Conference on Advanced Research in Business and Social Sciences.

Terziev, V. K. (2017c). Research of the management skills and abilities and of the management effectiveness of the cadets. Prague, Czech Republic: CBU International Conference: Innovations in Science and Education. 